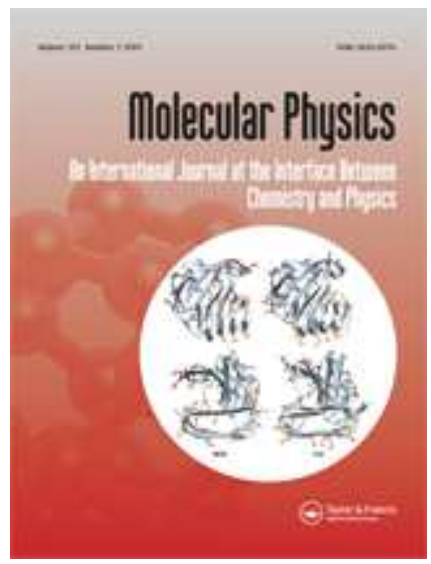

\title{
Vapour pressure of ionic liquids
}

\begin{tabular}{|c|c|}
\hline Journal: & Molecular Physics \\
\hline Manuscript ID: & TMPH-2009-0422.R1 \\
\hline Manuscript Type: & Full Paper \\
\hline $\begin{array}{r}\text { Date Submitted by the } \\
\text { Author: }\end{array}$ & 31-Dec-2009 \\
\hline Complete List of Authors: & $\begin{array}{l}\text { Bier, Markus; Max Planck Institute for Metals Research, Department } \\
\text { Dietrich } \\
\text { Dietrich, Siegfried; Max Planck Institute for Metals Research, } \\
\text { Department Dietrich }\end{array}$ \\
\hline Keywords: & vapour pressure, ionic liquids, triple point \\
\hline
\end{tabular}

\section{s ScholaroNE \\ Manuscript Central}


Molecular Physics

Vol. 00, No. 00, Month 200x, 1-7

\title{
RESEARCH ARTICLE
}

\section{Vapour pressure of ionic liquids}

\author{
Markus Bier* and S. Dietrich \\ Max-Planck-Institut für Metallforschung, Heisenbergstr. 3, 70569 Stuttgart, Germany \\ and Institut für Theoretische und Angewandte Physik, Universität Stuttgart, \\ Pfaffenwaldring 57, 70569 Stuttgart, Germany \\ (31 December 2009)
}

\begin{abstract}
We argue that the phenomenon of extremely low vapour pressures of room temperature ionic liquids near their triple points are not due to Coulombic interactions alone but due to the combination of strong ionic characters and of low melting temperatures. The arguments given are independent of the substance and not model specific thereby demonstrating the generality of the phenomenon.
\end{abstract}

Keywords: vapour pressure; ionic liquids; triple point

An extremely low vapour pressure (e.g. ca. $100 \mathrm{pPa}$ at $298 \mathrm{~K}$ for $\left[\mathrm{C}_{4} \mathrm{mim}\right]\left[\mathrm{PF}_{6}\right][1]$ compared with $3 \mathrm{kPa}$ at $298 \mathrm{~K}$ for $\mathrm{H}_{2} \mathrm{O}[2]$ ) is one of the extraordinary properties of room temperature ionic liquids (RTILs), i.e. molten salts with melting points below $100^{\circ} \mathrm{C}$. As a consequence, RTILs such as $\left[\mathrm{C}_{4} \mathrm{mim}\right]\left[\mathrm{PF}_{6}\right]$ at $298 \mathrm{~K}$ are liquids which do not evaporate significantly even under ultrahigh vacuum (UHV) conditions (i.e. for a pressure range $100 \mathrm{nPa} \ldots 100 \mathrm{pPa}[3]$ ), which offers the possibility to use RTILs, e.g. as substitutes for volatile organic solvents $[4,5]$. Only a decade ago RTILs were still described as "non-volatile" [4], but meanwhile direct measurements of their vapour pressures and enthalpies of vapourisation at elevated temperatures have been carried out [6, 7]; even the distillation of RTILs [8] has been achieved. Since non-ionic liquids (NILs, such as benzene and water) exhibit triple point pressures $p_{3}$ above $1 \mathrm{~Pa}$ (see Table 1(a)), one might be tempted to attribute the extremely low triple point pressures of RTILs exclusively to their ionic character. However, a comparison of RTILs, which are composed of organic ions, with inorganic fused salts (IFSs), which are also of ionic character, reveals that the triple point pressures of the latter are above $1 \mathrm{~Pa}$ (see Table 1(c)), such as for NILs. This rules out the ionic character as the only reason for the low triple point pressures of RTILs.

We shall show below that it is not the Coulomb interaction alone but the combination of the melting point to occur below room temperature and of the ionic character which leads to the observed low triple point pressures of RTILs. In other words, it will be argued that any substance with a strong ionic character which is fluid at room temperature inevitably exhibits extremely low vapour pressures near its triple point. As it is apparent from the discussion above on NILs, RTILs and IFSs, low melting temperatures and ionic interactions are independent and non-contradicting properties and it is precisely the class of RTILs for which both properties are present simultaneously. Moreover, a comparison of NILs and RTILs

Corresponding author. Email: bier@mf.mpg.de

ISSN: 0040-5167 print/ISSN 1754-2278 online

(C) 200x Taylor \& Francis

DOI: $10.1080 / 0040516 Y Y x x x x x x x x$

http://www.informaworld.com 
shows that low melting temperatures alone do not imply low triple point pressures. The arguments presented are of general nature and do not resort to a specific model. Moreover, we shall not address the mechanism leading to the low standard melting temperatures of RTILs, which has been explained in terms of a frustrated crystallisation due to asymmetric ion shapes, charge delocalisation, packing inefficiency and conformational degeneracy [9-12]. All what is needed for our line of arguments is a low melting temperature - irrespective of its origin for an actual substance or a specific model under consideration.

Figure 1 displays the experimental vapour pressures $p_{\text {sat }}(T)$ for liquid-vapour coexistence at temperature $T$ for the non-polar liquid benzene $\left(\mathrm{C}_{6} \mathrm{H}_{6}\right.$, see Reference [2]), the hydrogen bond forming liquid water $\left(\mathrm{H}_{2} \mathrm{O}\right.$, see Reference [2]), the paradigmatic RTILs $\left[\mathrm{C}_{4} \mathrm{mim}\right][\mathrm{dca}],\left[\mathrm{C}_{2} \mathrm{mim}\right]\left[\mathrm{NTf}_{2}\right]$ and $\left[\mathrm{C}_{8} \mathrm{mim}\right]\left[\mathrm{NTf}_{2}\right]$ (see References $[7,13])$, as well as fused cadmium chloride $\left(\mathrm{CdCl}_{2}\right)$ and sodium chloride $(\mathrm{NaCl})$ as representatives of IFSs (see Reference [14]). At low temperatures the boiling curves terminate at the triple point temperature $T_{3}$ (see Table 1 and References $[2,15-17]$ ), which is close the standard melting temperature of the corresponding substance because the melting curve is very steep. At high temperatures the boiling curves of the NILs and the IFSs terminate at their critical temperatures $T_{c}$ (see Tables 1(a) and (c) and References $[2,18]$ ), whereas RTILs decompose at a substance specific decomposition temperature $T_{d}$ (see Table $1(\mathrm{~b}$ ) and References $[4,15,19])$. As it is apparent from Figure 1, RTILs do not boil at ambient pressure $p_{0}=10^{5} \mathrm{~Pa}$ because boiling is preempted by decomposition; consequently Table 1(b) displays only extrapolated standard boiling temperatures $T_{b}^{\text {extr }}$ for RTILs.

In order to understand the position of the boiling curves of RTILs in Figure 1, we note that with respect to the strength of the particle-particle interaction, RTILs lie in between NILs, which interact via relatively weak dispersion forces and possibly hydrogen bonds, and IFSs, which interact predominantly via strong Coulomb forces. Due to the larger size of the RTIL ions and a possible delocalisation of the charge their interaction is, however, weaker than that of IFS ions. Hence, ignoring for the time being the decomposition of RTILs at $T_{d}$, the molar enthalpies of vapourisation $\Delta_{\mathrm{vap}} H(p)>0$ at pressure $p$ are expected to be ordered as $\Delta_{\text {vap }} H^{\mathrm{NIL}}(p)<\Delta_{\text {vap }} H^{\mathrm{RTIL}}(p)<\Delta_{\text {vap }} H^{\mathrm{IFS}}(p)$. On the other hand, in the spirit of Trouton's rule [20], the molar entropies of vapourisation $\Delta_{\text {vap }} S(p)$ at pressure $p$ are expected to depend only weakly on the kind of substance, because their values are dominated by the translational and rotational degrees of freedom whereas vibrational and electronic modes and the structural arrangements contribute only as small corrections [21]. Data for organic and inorganic liquids tabulated in References $[16,22]$ suggest a Trouton-like rule $\Delta_{\text {vap }} S\left(p_{0}\right) \approx(95 \pm 15) \mathrm{J} / \mathrm{mol}$ at ambient pressure $p_{0}=10^{5} \mathrm{~Pa}$. According to $\Delta_{\mathrm{vap}} H(p)=T_{b}(p) \Delta_{\mathrm{vap}} S(p)[20]$ with $T_{b}(p)$ denoting the boiling temperature at pressure $p$ one expects the relation $T_{b}^{\mathrm{NIL}}(p)<T_{b}^{\mathrm{RTIL}}(p)<T_{b}^{\mathrm{IFS}}(p)$, which is indeed consistent with the experimental findings for NILs and IFSs $[2,16,22]$ and the extrapolations for RTILs to ambient pressure [23] (see also Figure 1 and Table 1). Away from the critical point $\Delta_{\text {vap }} H(p)$ and $\Delta_{\text {vap }} S(p)$ depend only weakly on $p[2,16]$, such that we can approximate $\Delta_{\text {vap }} H(p) \approx \Delta_{\text {vap }} H\left(p_{0}\right)$ and $\Delta_{\text {vap }} S(p) \approx \Delta_{\text {vap }} S\left(p_{0}\right)$ for a certain reference pressure $p_{0}$ such as the ambient pressure. Within this approximation the ClausiusClapeyron equation [20] allows one to estimate the vapour pressure $p_{\text {sat }}(T)$ for liquid-vapour coexistence at temperature $T$ :

$$
p_{\text {sat }}(T) \approx p_{0} \exp \left(-\frac{\Delta_{\text {vap }} H\left(p_{0}\right)}{R T}+\frac{\Delta_{\text {vap }} S\left(p_{0}\right)}{R}\right) .
$$


According to the above reasoning concerning $\Delta_{\text {vap }} H$ and $\Delta_{\text {vap }} S$ one infers the relation

$$
p_{\mathrm{sat}}^{\mathrm{NIL}}(T) \gg p_{\mathrm{sat}}^{\mathrm{RTL}}(T) \gg p_{\mathrm{sat}}^{\mathrm{IFS}}(T) .
$$

Actually, liquid-vapour coexistence at $p_{\text {sat }}(T)$ occurs only in the temperature ranges $T_{3} \leq T \leq T_{c}$ for NILs and IFSs and $T_{3} \leq T \leq T_{d}$ for RTILs (see Figure 1).

Equation (2) follows from general considerations concerning the strength of the particle-particle interaction and the entropy of vapourisation. According to these simple arguments it is indeed the strong ionic character which leads to a downshift of the boiling curves $p_{\text {sat }}(T)$ of RTILs relative to those of NILs. However, the reason for IFSs having not an even lower triple point pressure than RTILs is the large difference in the triple point temperatures $\left(T_{3}^{\mathrm{RTIL}}<T_{3}^{\mathrm{IFS}}\right.$, see Table 1) induced by a large difference in standard melting temperatures. Hence the extremely low vapour pressures of RTILs near their triple points can be understood on very general grounds based on both a strong ionic character and low melting temperatures; the conclusions are independent of substance specific properties which explains why this phenomenon is a common feature of RTILs.

In summary, we have shown that near its triple point the vapour pressure of a room temperature ionic liquid of strong ionic character is very small, because it depends exponentially on the ratio of a large enthalpy of vapourisation which is almost as large as that of inorganic salts - and a small thermal energy near the triple point, which is as small as that of non-ionic liquids. According to $p_{\text {sat }}(T) \sim \exp \left(-\Delta_{\text {vap }} H /(R T)\right)$, where the prefactor is approximately independent of the kind of substance, an increase of $\Delta_{\text {vap }} H$, reflecting the ionic character of room temperature ionic liquids relative to non-ionic liquids, leads to a downshift of $p_{\text {sat }}(T)$. For room temperature ionic liquids these low vapour pressures are physically accessible due to their low triple points, induced by their low melting temperature - which is part of the definition of room temperature ionic liquids (see Figure 1). The even stronger ionic character of inorganic fused salts would in principle lead to even lower vapour pressures; however, these cannot be reached for their liquid state because they are preempted by a significantly higher freezing and thus triple point temperature (see Figure 1).

\section{References}

[1]Y. U. Paulechka, G. J. Kabo, A. V. Blokhin, O. A. Vydrov, J. W. Magee and M. Frenkel, J. Chem. Eng. Data 48, 457 (2003).

[2] E. W. Lemmon, M. O. McLinden and D. G. Friend, Thermophysical Properties of Fluid Systems, in NIST Chemistry WebBook, NIST Standard Reference Database Number 69, edited by P. J. Linstrom and W. G. Mallard, http://webbook.nist.gov

[3] P. A. Redhead, J. Vac. Sci. Technol. A 21, S12 (2003).

[4]P. Wasserscheid and W. Keim, Angew. Chem. Int. Ed. 39, 3773 (2000).

[5]R. Ludwig and U. Kragl, Angew. Chem. Int. Ed. 46, 6582 (2007).

[6]Y. U. Paulechka, Dz. H. Zaitsau, G. J. Kabo and A. A. Stechan, Thermochim. Acta 439, 158 (2005).

[7]Dz. Zaitsau, G. J. Kabo, A. A. Stechan, Y. U. Paulechka, A. Tschersich, S. P. Verevkin and A. Heintz, J. Phys. Chem. A 110, 7303 (2006).

[8] M. J. Earle, J. M. S. S. Esperança, M. A. Gilea, J. N. C. Lopes, L. P. N. Rebelo, J. W. Magee, K. R. Seddon and J. A. Widegren, Nature 439, 831 (2005).

[9]K. R. Seddon, J. Chem. Tech. Biotechnol. 68, 351 (1997).

[10] A. S. Larsen, J. D. Holbrey, F. S. Tham and C. A. Reed, J. Am. Chem. Soc. 122, 7264 (2000).

[11]J. D. Holbrey, W. M. Reichert, M. Nieuwenhuyzen, S. Johnston, K. R. Seddon and R. D. Rogers, Chem. Commun. 2003, 1636.

[12] N. V. Plechkova and K. R. Seddon, Chem. Soc. Rev. 37, 123 (2008).

[13] V. N. Emel'yanenko, S. P. Verevkin and A. Heintz, J. Am. Chem. Soc. 129, 3930 (2007).

[14]J. L. Barton and H. Bloom, J. Phys. Chem. 60, 1413 (1956).

[15] C. P. Fredlake, J. M. Crosthwaite, D. G. Hert, S. N. V. K. Aki and J. F. Brennecke, J. Chem. Eng. Data 49, 954 (2004).

[16] D. R. Lide (Ed.), CRC Handbook of Chemistry and Physics (CRC Press, Boca Raton, 1998). 
[17]Y. U. Paulechka, A. V. Blokhin, G. J. Kabo and A. A. Stechan, J. Chem. Thermodyn. 39, 866 (2007). [18]P. J. McGonigal, J. Phys. Chem. 67, 1931 (1963).

[19] H. Tokuda, K. Hayamizu, K. Ishii, M. A. Bin Hasan Susan and M. Watanabe, J. Phys. Chem. B 109, $6103(2005)$.

[20]P. W. Atkins, Physical chemistry, 6th Ed. (Oxford University Press, Oxford, 1998).

[21]P. S. Vincett, J. Phys. Chem. 82, 2797 (1978).

[22] G. J. Janz, Molten Salts Handbook (Academic Press, New York, 1967).

[23] L. P. N. Rebelo, J. N. C. Lopes, J. M. S. S. Esperança and E. Filipe, J. Phys. Chem. B 109, 6040 (2005). 


\section{Tables}




\begin{tabular}{|l|c|c|c|c|l|}
\hline (a) NIL & $T_{3} / \mathrm{K}$ & $p_{3} / \mathrm{Pa}$ & $T_{b} / \mathrm{K}$ & $T_{c} / \mathrm{K}$ & References \\
\hline $\mathrm{C}_{6} \mathrm{H}_{6}$ & 278.7 & 4799 & 353.2 & 562.1 & {$[2]$} \\
$\mathrm{H}_{2} \mathrm{O}$ & 273.2 & 611.7 & 373.1 & 647.1 & {$[2]$} \\
\hline
\end{tabular}

\begin{tabular}{|l|c|c|c|c|l|}
\hline (b) RTIL & $T_{3} / \mathrm{K}$ & $p_{3} / \mathrm{Pa}$ & $T_{d} / \mathrm{K}$ & $T_{b}^{\text {extr }} / \mathrm{K}$ & References \\
\hline$\left[\mathrm{C}_{4} \mathrm{mim}\right][\mathrm{dca}]$ & 267 & $1.5 \times 10^{-13}$ & 695 & 719 & {$[13,15]$} \\
{$\left[\mathrm{C}_{2} \mathrm{mim}\right]\left[\mathrm{NTf}_{2}\right]$} & 271 & $8.9 \times 10^{-12}$ & 712 & 906 & {$[7,17,19]$} \\
{$\left[\mathrm{C}_{8} \mathrm{mim}\right]\left[\mathrm{NTf}_{2}\right]$} & 264 & $7.8 \times 10^{-14}$ & 698 & 857 & {$[7,17,19]$} \\
\hline
\end{tabular}

\begin{tabular}{|l|c|c|c|c|l|}
\hline (c) IFS & $T_{3} / \mathrm{K}$ & $p_{3} / \mathrm{Pa}$ & $T_{b} / \mathrm{K}$ & $T_{c} / \mathrm{K}$ & References \\
\hline $\mathrm{CdCl}_{2}$ & 837 & 214 & 1233 & $?$ & {$[14,16]$} \\
$\mathrm{NaCl}$ & 1074 & 46 & 1738 & $>3400$ & {$[14,16,18]$} \\
\hline
\end{tabular}

Table 1. Experimental data for characteristic temperatures of (a) non-ionic liquids (NILs), (b) room temperature ionic liquids (RTILs) and (c) inorganic fused salts (IFSs) corresponding to the substances discussed in Figure 1. $T_{3}$ and $p_{3}$ denote the temperature and the pressure, respectively, at the triple point, $T_{c}$ is the critical temperature and $T_{d}$ denotes the temperature for the onset of decomposition of an RTIL $[15,19] . T_{b}$ denotes the standard boiling temperature at ambient pressure $p_{0}=10^{5} \mathrm{~Pa}$ for NILs and IFSs, whereas the standard boiling temperatures $T_{b}^{\text {extr }}$ for RTILs are estimated by extrapolation [23] because boiling of RTILs is preempted by decomposition. 


\section{Figure captions}

Figure 1. Experimental vapour pressures $p_{\text {sat }}(T)$ at liquid-vapour coexistence of non-ionic liquids (NILs), room temperature ionic liquids (RTILs) and inorganic fused salts (IFSs) as a function of temperature $T$ for the non-polar liquid benzene $\left(\mathrm{C}_{6} \mathrm{H}_{6}\right.$, see Reference [2]), the hydrogen bond forming liquid water $\left(\mathrm{H}_{2} \mathrm{O}\right.$, see Reference [2]), the paradigmatic RTILs $\left[\mathrm{C}_{4} \mathrm{mim}\right][\mathrm{dca}],\left[\mathrm{C}_{2} \mathrm{mim}\right]\left[\mathrm{NTf}_{2}\right]$ and $\left[\mathrm{C}_{8} \mathrm{mim}\right]\left[\mathrm{NTf}_{2}\right](\mathrm{see}$ References [7, 13]), as well as fused cadmium chloride $\left(\mathrm{CdCl}_{2}\right)$ and sodium chloride $(\mathrm{NaCl})$ as examples of IFSs (see Reference [14]). At low temperatures all curves terminate at the corresponding triple point temperature $T_{3}$ (see Table 1 ), which is close to the standard melting temperature of that substance. At high temperatures the boiling curves for the RTILs terminate at the decomposition temperature $T_{d}$, whereas the boiling curves of the other liquids end at their critical points (see Table 1 ). Room temperature $T_{0}=298 \mathrm{~K}$ and ambient pressure $p_{0}=10^{5} \mathrm{~Pa}$ are indicated. 


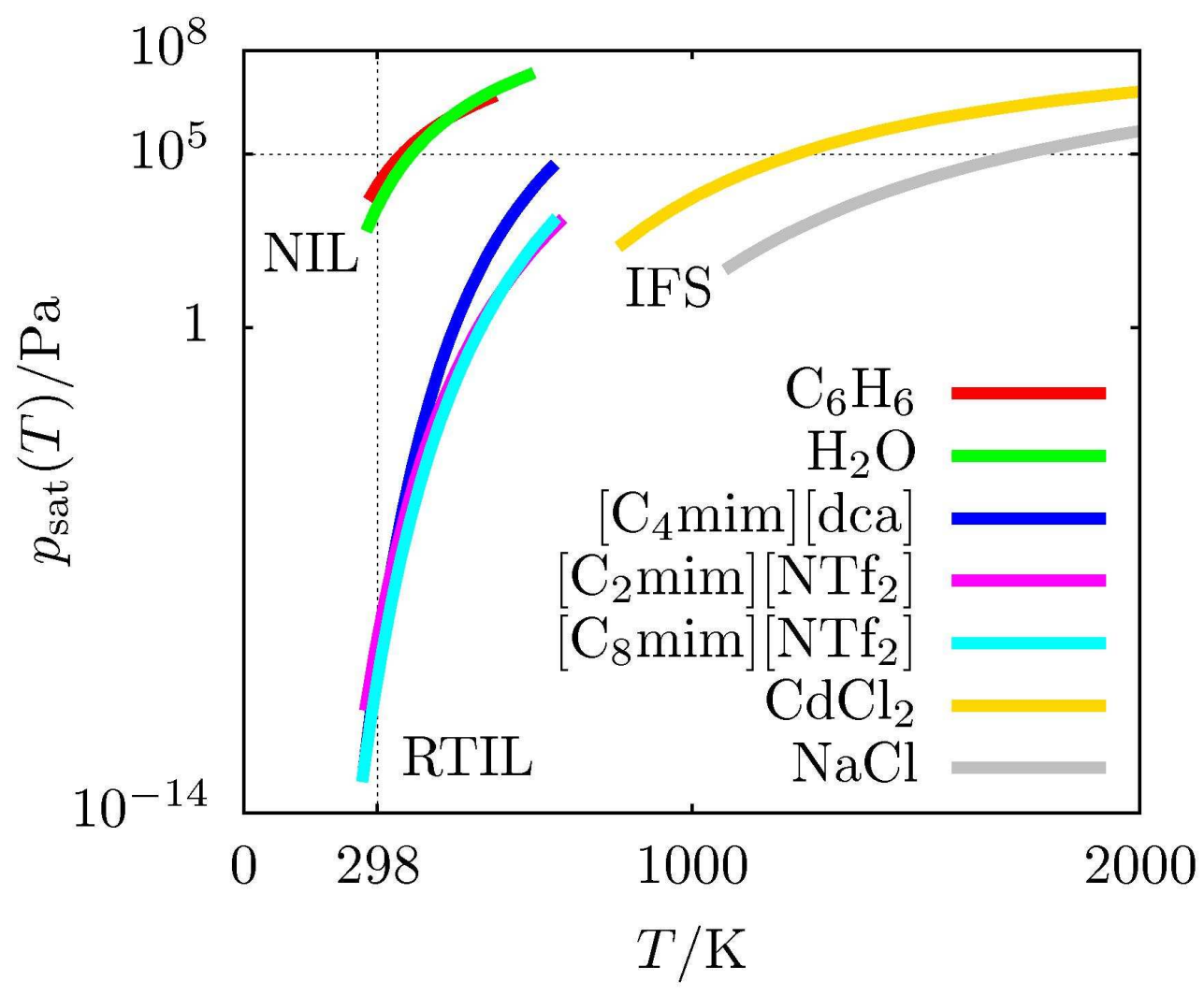

$75 \times 60 \mathrm{~mm}(600 \times 600$ DPI $)$ 